\title{
Using urban foresight techniques in city visioning: lessons from the Reading 2050 vision
}

Article

Published Version

Creative Commons: Attribution-Noncommercial 4.0

Open Access

Dixon, T., Montgomery, J., Horton-Baker, N. and Farrelly, L. (2018) Using urban foresight techniques in city visioning: lessons from the Reading 2050 vision. Local Economy, 33 (8). pp. 777-799. ISSN 1470-9325 doi:

https://doi.org/10.1177/0269094218800677 Available at https://centaur.reading.ac.uk/78852/

It is advisable to refer to the publisher's version if you intend to cite from the work. See Guidance on citing.

To link to this article DOI: http://dx.doi.org/10.1177/0269094218800677

Publisher: SAGE Publications

All outputs in CentAUR are protected by Intellectual Property Rights law, including copyright law. Copyright and IPR is retained by the creators or other copyright holders. Terms and conditions for use of this material are defined in the End User Agreement.

www.reading.ac.uk/centaur 
Central Archive at the University of Reading

Reading's research outputs online 


\title{
Using urban foresight
} techniques in city visioning: Lessons from the Reading 2050 vision

Local Economy $0(0) 1-23$

(C) The Author(s) 2018

(c) (i) (5)

Article reuse guidelines: sagepub.com/journals-permissions DOI: I0.1 I77/02690942। 8800677 journals.sagepub.com/home/lec

(SAGE

\section{Tim Dixon}

University of Reading, UK

\section{Jenni Montgomery}

Barton Willmore, UK

\section{Nigel Horton-Baker}

Reading UK CIC, UK

\section{Lorraine Farrelly}

University of Reading, UK

\begin{abstract}
The emergence of urban (or city) foresight techniques focuses on the need to create coherent city visions to plan and manage for future long-term change and create opportunities for new investment into the local urban economy. This paper reviews the concepts of 'co-created' city visioning and urban foresight, setting this in the context of new and emerging practice and policy in the UK, and elsewhere. The paper critically reviews the development of the vision for a small city (the 'Reading 2050' project, linked to the UK Future of Cities Foresight Programme), and the lessons it holds for visioning, foresight and planning, using the 'quadruple helix' framework as a conceptual lens for analysis.
\end{abstract}

\section{Keywords}

city visions, co-creation, quadruple helix, urban foresight, visioning 


\section{Introduction}

Today a majority of the world's population is urbanised, and this is set to grow substantially over the next 30-40 years. In England and Wales, already $82 \%$ of the population lives in cities (Office for National Statistics (ONS), 2013), with some 54\% living in the largest 64 'primary urban areas' (Champion, 2016). Cities are closely associated with problems of resource depletion, climate change and growing socio-economic disparity, but also provide opportunities for solving the same problems because of economies of scale, and their role as centres of innovation and social learning (Dixon and Eames, 2013). There has therefore been a growing focus on 'urban sustainability' (or 'a holistic perspective of urban areas and their impact on the rest of the planet' (MISTRA, 2014)), and, more generally, on how cities can plan more effectively for their long-term futures (Iwaniec and Wiek, 2014).

The focus on sustainability in cities also inherently invites the question, what sort of a sustainable future can be envisaged for the city in question? In the context of urban planning, the idea of 'visioning' (or having a clear and formal sense of where the city wants to be in the long term (25 years or more)) emerged during the 1980s and 1990s, particularly in the USA, not only as a way of understanding the future, but also to plan for a desirable, or preferred, set of sustainable outcomes (see for example, Atlanta, and Portland) (Gaffikin and Sterrett, 2006). Newman and Jennings (2008) also highlight 'successful' examples of city visions in Perth, Vancouver and Chicago during this period. This emergence of thinking about the future of cities also reflected a growing body of literature focusing on 'visioning sustainability' in a range of other contexts, such as energy futures (Wiek and Iwaniec, 2014). More recently, over the last 10-15 years, we have also seen the development of more 'formal' visioning processes (or what might be termed 'urban foresight', or 'city foresight' methods) in cities and urban areas which have been used to develop city visions (see, for example, Phoenix, USA; Johannesburg and Vancouver; Iwaniec and Wiek, 2014; Newman and Jennings, 2008).

Despite these examples, there is still a shortage of rigorous and analytically sound city visions (Wiek and Iwaniec, 2014), and perhaps even a 'withdrawal' from the more visionary futures-based aspects of urban planning that were prominent in its origins (Fernández Güell and Redondo, 2012). This reflects a number of factors in the context of urban planning, including a common focus on relatively short-term urban planning horizons of 15-20 years; a perception that long-term thinking is inherently complex; the relatively short-term nature of electoral cycles; and the degree of 'comfort' gained from thinking about the everyday (Freestone, 2012; Swain, 2016).

Until recently, examples of city visions therefore were also relatively uncommon in a UK urban planning context (Swain, 2016). However, the emergence of the UK Government Office of Science (GoS) Future of Cities Programme (2013-2016) highlighted the importance of 'city foresight', founded on the science of thinking about the future of cities, and which can be used to enable city stakeholders to explore urban futures not only in a local and regional context, but as part of a wider connected network of cities (Cowie et al., 2016; GoS, 2016a, 2016b). A number of city visions have been created as part of this programme, resulting from partnerships between academia, local authorities, business and civil society (the combination of which form the basis of the 'quadruple helix' (QH) model of innovation 
(Arnkil et al., 2011; Goddard and TewdwrJones, 2016)).

This paper therefore explores and critically reviews the development of a vision for a small city (Reading in Berkshire, England). To do this, the paper begins by reviewing what is meant by 'city visioning' and 'urban foresight', setting this in the context of new and emerging practice and policy in the UK, and elsewhere. The paper then describes the emergence of 'urban foresight' methods and techniques which offer a potentially 'participatory' approach to city visioning, before examining the concept of the 'quadruple helix' model of innovation which provides a conceptual 'lens' through which to view the interactions and interrelationships of universities, government, business and civic society. The paper describes the aim and objectives of the research behind the 'Reading 2050' vision, as one of the city vision projects in the UK GoS Future of Cities Programme (GoS, 2016a), and the urban foresight methods used to develop the vision. Finally, the paper uses the critical lens of the $\mathrm{QH}$ model to set out the main lessons learned from the Reading 2050 research in terms of: (i) the urban foresight methods used; (ii) the roles and responsibilities of stakeholder groups in the development of the vision, and (iii) the further development and implementation of the vision.

In providing this critical review it is important to note that although the authors have been involved in the development of the vision, the paper has been written (as far as is possible) to offer an independent, transparent and critical insight into the development of the Reading 2050 vision and what lessons it holds for other cities seeking to develop city visions. In this sense we see the research which underpins the development of the vision as including elements of 'reflexive research' (Iwaniec and Wiek, 2014). As Iwaniec (2013) emphasises, such collaboration between city vision 'practice' and 'research' is intended to take advantage of collaborative dynamics, and to act as a mode of reflexivity in research and practice. Finally, given the fact that the vision was launched in October 2017 the paper focuses on the period of its initial development prior to this, and its implementation thus far (to mid-2018).

\section{Background and context}

\section{City visioning: Origins and concepts}

Visions have played their part throughout history in the inspiration of imagined futures, ranging from biblical visions, through to the writings of Plato and Thomas More (Bruce, 2008; Dunn et al., 2014). Essentially a well-crafted and inspiring vision has the capacity to influence the planning of decisions, actions and behaviours that can inspire change and transform individuals. A vision can be defined formally as a 'desirable state in the future' (Wiek and Iwaniec, 2014: 1), and 'visioning' is the process of creating a vision.

During the latter part of the twentieth century, the need to engage directly with the sustainability agenda (and to aspire to live within environmental, social and economic limits for the sake of future generations) led governments, companies, nonprofit organisations and wider civic society to think formally about visions for a sustainable and desirable future; for example, the Earth Charter, 2000 was a leading example of this thinking (Costanza, 2000; Iwaniec and Wiek, 2014; Newman and Jennings, 2008; Weaver and Rotmans, 2006). Although, as Gaffikin and Sterrett (2006) suggested, many commentators had previously lamented planning's apparent loss of its original visionary and utopian traditions (Brooks, 1988; Freeman, 2012), the development of visioning and sustainability concepts and principles also played a role in the way in which some urban 
planners started to think about the future during the 1980s and 1990s (Iwaniec and Wiek, 2014). As a result, during this period a number of 'vision planning' activities emerged in the USA and UK. In the USA, this was particularly influenced by the development of community vision guidance, which promoted stakeholder engagement and participation in a shared vision (for example, Atlanta Vision 2020; Gaffikin and Sterrett, 2006). Similarly, Glasgow's earliest vision in the UK in 1995 was highlighted as an example of a co-created city vision (Gaffikin and Sterrett, 2006). Newman and Jennings (2008) also highlighted the importance of developing long-term city visions, citing Oregon, Perth, Vancouver and Chicago as good examples of collaborative city visions during the 1990s and early 2000s.

More recently, some cities have begun to develop visions relating to urban sustainability which are led by municipal planning departments and aim to build capacity and community development through participatory approaches to visioning. In the context of sustainable futures for cities, visions are seen as orienting strategic operational urban planning, as well as monitoring and adapting existing plans (John et al., 2015). McPhearson et al. (2016) suggest visions can therefore be used to explore plausible and desirable urban futures and to also help 'guide' and 'manage' sustainable transitions to these futures. Recent examples of this include the Rockefeller Foundation 100 Resilient Cities Project which requires cities to develop resilience plans (McPhearson et al., 2016), and the city visions for Vancouver (Greenest City by 2020) and Copenhagen (net zero carbon city by 2025). Recent academic literature also points to a diversity of dominant concepts and imaginaries in the content of 'desirable' and emerging city visions (John et al., 2015; Khan and Zaman, 2018). Amongst these, two important future city 'notions' are the 'smart city' based on the 'effective integration of physical, digital and human systems in the built environment to deliver a sustainable, prosperous and inclusive future for its citizens' (BSI, 2014), and the 'sustainable city' (for example, one that is able to meet the needs of the present without compromising the ability of future generations to meet their own needs; Hodson and Marvin, 2014). Other desirable notions for future cities such as eco-city; resilient city; and liveable city have also been posited (Khan and Zaman, 2018). Moreover, there is an increasing focus not only on whether smart cities can also deliver sustainable outcomes (Martin et al., 2018), but also the extent to which smart city visions (with their often inherent 'technocratic' focus) can truly engage citizens as active participants in the visioning process (Joss, 2018; Kummitha, 2018).

Despite this growing interest in visioning in relation to urban sustainability, the increasingly common use of the term 'vision' has often tended to mask and devalue its different meanings in the context of urban planning (Peel and Lloyd, 2005; Shipley and Newkirk, 1999). For example, Shipley and Newkirk (1999) differentiate between 'literal' meanings (where visions contain clear and specific images as in a masterplan), and 'metaphorical' visions (which capture values, policies and actions). They also distinguish between 'individual' visions and 'participative' approaches, which seek to engage with the wider community. Similarly, visions may be positive, or 'utopian' visions, or negative, 'dystopian' visions. These variations therefore potentially pose dangers which might result in different stakeholders interpreting and deploying visions differently, or simply using them to conjure up the cachet of the great urban plans of the past (Peel and Lloyd, 2005; Shipley and Newkirk, 1999).

Others have argued that urban planning today still continues to be unwilling to 
engage directly with the longer term (Royal Town Planning Institute (RTPI), 2014). This is an argument made not only in the UK (Ravetz and Miles, 2016; Swain, 2016) but also in other parts of the world (Freestone, 2012). Indeed, this perceived 'deficit' is also seen in the continued lack of formal 'futures studies' or 'foresight' techniques in urban planning, and the reasons for this have been summarised by authors such as Fernández Güell and Redondo (2012) and Freestone (2012). These include, for example, a common focus on the immediate present, rather than the longer-term, in urban planning. Similarly, planning, as government and local government practice, is not only linked to electorally-sensitive decision making and relatively short-term election cycles of 3-5 years, but must also reconcile a range of existing complex uncertainties about the future which are multiplied in the longer term. These uncertainties are also compounded by austerity, which has also affected many local authorities in the UK (Cowie et al., 2016; Ravetz and Miles, 2016).

In summary, with a few previous notable exceptions, urban planners have only intermittently and sporadically engaged with futures studies, or more formal foresight techniques, to develop long-term city visions in the UK and elsewhere (Eames et al., 2017; Fernández Güell and Lopez, 2016; Swain, 2016). Urban planning therefore remains a predominantly short-term and medium-term activity (or 15-20 years ahead), rather than looking to the longerterm of 2050 and beyond.

\section{The emergence of urban foresight methods}

Despite their relative scarcity, some of the more recent city visions can also be seen as reflecting a growing interest in formal 'urban (or city) foresight' methods and techniques. The origins of the term 'foresight' can be found in military planning studies which were initiated in the USA during the 1940s and 1950s, which developed into a wider focus on analysing the forces driving wider transformative change in technology and society (Fernández Güell, 2009). For example, the European Union (EU) (2011: 1) defines foresight as 'a systematic, participatory, future intelligence gathering and medium to long-term vision building process aimed at present day decisions and mobilizing joint actions'. As Holste et al. (2010) point out, foresight is therefore both a conceptual framework and a process of forward-looking analysis and decision-making that includes long- to medium-term considerations of possible futures.

The emphasis in foresight studies has traditionally not only been on long-term future orientation that goes beyond immediate issues and concerns, but also on the use of a range of methods (including 'visioning') which encourages participatory approaches to futures thinking. In mainland Europe the emergence of foresight has found a spatial focus with the development of the concept of 'territorial' (or regional) foresight studies, which are based around a structured set of participatory vision building and strategic planning activities that allow relevant stakeholder groups in regions to think, consider, debate and shape the medium to longterm future of their regions, provinces or cities (EU, 2011; Fernández Güell and Lopez, 2016).

In this context, urban (or city) foresight is a subset of wider 'territorial' foresight studies. For example, a recent UK report on the Future of Cities defined urban foresight as (GoS, 2016a: 7): ' . . the science of thinking about the future of cities. It draws on diverse methods to give decisionmakers comprehensive evidence about anticipated and possible future change'. 
Hartman (2011) suggests that there are two main forms of urban foresight study: firstly, generic studies, without a territorial focus but which combine a technology-based foresight perspective with urban development issues; and secondly, urban foresight with a territorial focus on specific cities and urban areas. The urban foresight techniques which are used are also diverse and may be quantitative (including forecasting and modelling), or qualitative (for example, visioning and backcasting; Eames et al., 2013; Fernández Güell, 2009).

In this context, 'backcasting' is often used to generate a desirable future, and then look backwards from that future to the present in order to strategise and to plan how it could be achieved (Eames et al., 2013; GoS, 2016a; Phdungsilp, 2011). This approach is distinguishable from other methods, such as forecasting and scenario building, which are projective in nature, and so backcasting has gained a wide degree of acceptance as an important tool in urban futures research (Eames et al., 2017). As part of this process, "visual conversations' (for example, descriptive writings and creative speculation) can also be used as a participatory method to help generate, facilitate and represent the various views of multiple actors on what the city might look like (Pollastri et al., 2016; Wiek and Iwaniec, 2014). Visioning itself can therefore be used to generate a picture of a desirable future, and is a key stage of any backcasting process.

Fernández Güell and Lopez (2016) provide a helpful analysis of 20 recent urban foresight studies examining their conceptualisation, methodological approach and overall impact and highlight five important groups: EU-based initiatives; local city led initiatives; corporate studies; architectural studies; and academic studies. Indeed, a number of recent academic-led studies which have focused on the urban sustainability of particular cities have used urban foresight techniques (for example, 'sustainable city region' (Ravetz, 2000); EPSRC Retrofit 2050 programme (Dixon et al., 2014; Eames et al., 2017); 'London 2062' (Bell and Paskins, 2012); 'Visions and Pathways VP40' in Australia (Ryan et al., 2016); and the 'General Plan, Arizona' in the USA mentioned earlier in this paper (Iwaniec and Wiek, 2014)).

Despite this, observers have also pointed out the limitations of such studies. For example, such initiatives can sometimes overlook functional and spatial complexity in cities (Fernández Güell and Lopez, 2016); The quality of the studies may also be influenced by the shape and form of vision leadership (i.e. corporate, local government or academic-led), and this not only raises the issue of whose vision really is being developed for a city, but also the sense that successful visions need to be pluralistic in nature (McPhearson et al., 2016; Ravetz and Miles, 2016). Finally, there are practical issues: for example, in quantitative foresight studies there may be a lack of high quality data (Hartman, 2011), with doubts expressed about whether visioning generally really does make a difference in complementing shorter term urban spatial planning (Shipley and Michela, 2006).

For its proponents, however, urban (or city) foresight offers key advantages for thinking about the future of cities (Eames et al., 2013; Fernández Güell and Lopez, 2016; Fernández Güell and Redondo, 2012; Kubeczko et al., 2011). Firstly, a variety of plausible and coherent future visions can be developed through participatory processes with key actors, which include the general public (although the influence of power relations must be recognised; Krzywosszynska et al., 2016). Secondly, a wide range of stakeholder engagement can produce tangible strategies to cope with anticipated future environmental and socio-economic change over a longer term than is conventionally the case with urban spatial planning. 
Thirdly, the development of expert networks can exchange and disseminate knowledge and outputs to a variety of stakeholders and decision-makers. Fourthly, not only can capacity and knowledge be increased through the development of networks and communication of results, but also long term investor confidence can be built in the local economy (GoS, 2016a).

\section{The Quadruple Helix $(\mathrm{QH})$ and co-created city visions}

As a result of the growing academic interest in urban foresight, there have been renewed calls for cities themselves to think more formally about their futures, particularly during the longer term (GOS, 2016a). The emphasis in the UK in this respect has been less on placing urban planners centre stage as leaders of the visioning process, but more on the collaborative development of city visions, with universities, government (across local, regional and national scales), industry, and citizens working together (Cowie et al., 2016; GOS, 2016a). This concept of collaboration is often associated with the development of a 'quadruple' helix conceptualisation of the innovation process, which has emerged from a European Commission policy focus on civic engagement and open innovation (Arnkil et al., 2011; Goddard and TewdwrJones, 2016; Kimatu, 2016; TewdwrJones, 2017).

This new innovation model also sees the 'triple helix' perspective (university, government and business) as limiting, and lacking a 'civil society' (or citizen) focus (Arnkil et al., 2011; Goddard et al., 2014). Critics, for example, have questioned the effectiveness of the model as expected levels of innovation and economic growth have often failed to materialise (McAdam and Debackere, 2017). In the new QH model there is therefore an emphasis not on three, but on four groups working together to drive innovation and structural change: civil society is therefore an additional source of knowledge which is required to 'shape and test' university research (Arnkil et al., 2011; Goddard and Tewdwr-Jones, 2016; Tewdwr-Jones, 2017). The fourth element of the helix is, however, far from being well-established in innovation research, and there is often disagreement over its precise constitution: for example, the extent to which it includes innovation 'users' as well as civil society (Hogland and Linton, 2017). Nonetheless, recent work has highlighted the usefulness of the QH as a way of conceptualising the participatory approach to vision development in smart cities (Mora et al., 2018; van Waart et al., 2015). For example, van Waart et al. (2015) see vision development as a collaborative process which helps shape the 'participatory domain' (Figure 1). This views the innovation process not as linear, but as layered, shaped and influenced by the relationships between the primary stakeholder groups (Carayannis and Campbell, 2010). In other words, QH represents a 'matrix model' where society and citizens can drive research priorities as well as react to research findings (Goddard and TewdwrJones, 2016). Indeed, further work by Garcia-Teran and Skoglund (2018) has also highlighted the value of $\mathrm{QH}$ as a 'processual' model in innovation studies.

The $\mathrm{QH}$ model also raises the issue of the role of Universities in their local and regional contexts because of their substantial economic weight and influence (Goddard and Vallance, 2013; Royal Society for the Arts (RSA), 2014). For example, as Goddard and Kempton (2016) highlight, there may be tensions between the expansion of a University's estate and student housing and the needs of the city in which the University is located, or indeed the desire not only to partner with larger successful multinationals rather than smaller local SMEs, but also to focus on international research rather than more local and regional scale city research. 


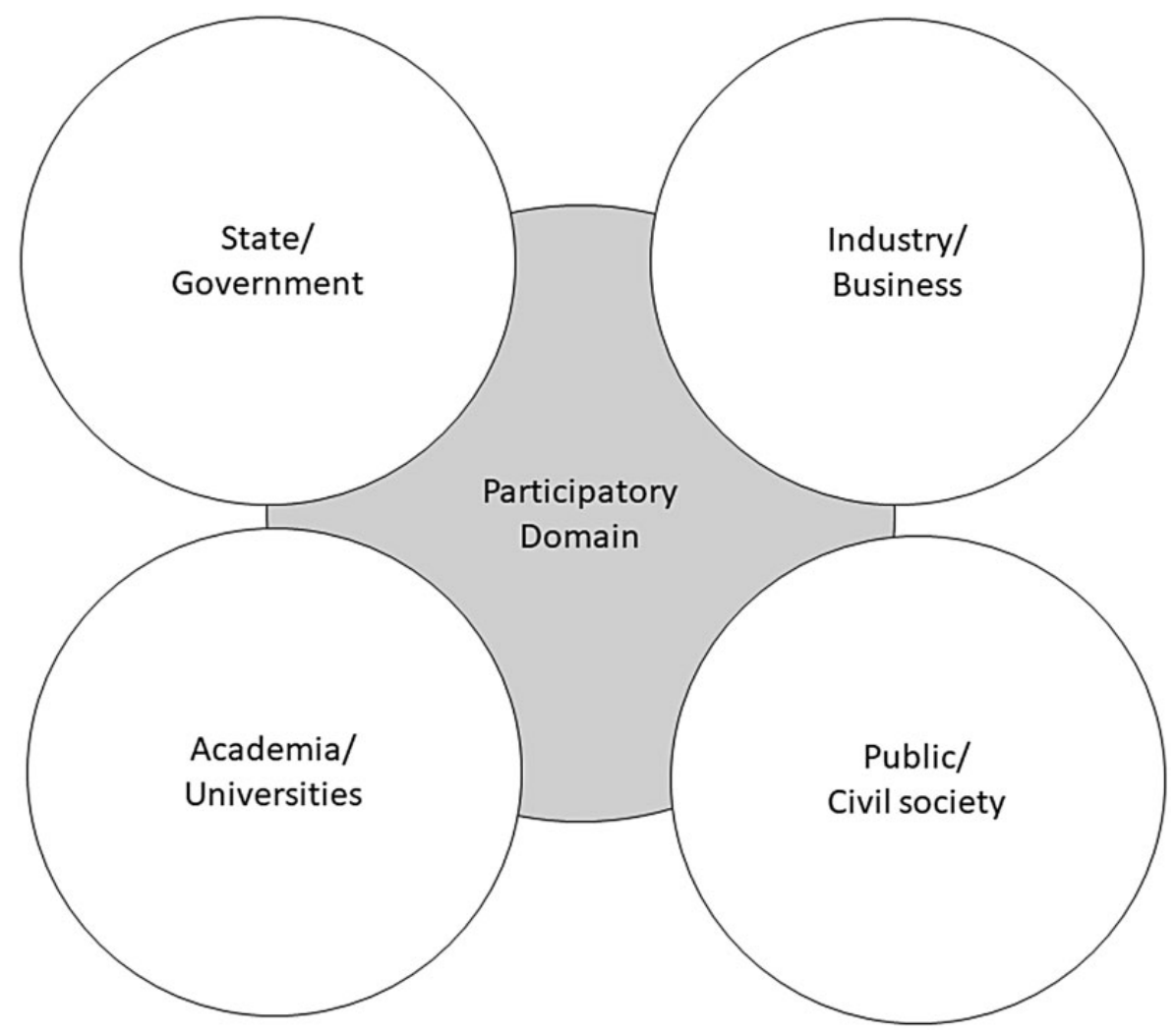

Figure I. Quadruple helix in the participatory domain (van Waart et al., 20I5).

Despite these tensions the $\mathrm{QH}$ concept is founded on a growing recognition that, as trusted 'anchor institutions', universities can play important civic, economic, and 'place leadership' roles within the cities in which they are located (Goddard and Kempton, 2016; Goddard and TewdwrJones, 2016; Goddard and Vallance, 2013; Hambleton, 2014). These roles can be potentially fulfilled through fostering networks across the public and private sectors, by identifying gaps in city intelligence and data gathering, and becoming more actively involved in city visioning processes (Goddard and Tewdwr-Jones, 2016).

Universities can therefore fulfil a crucial role in the 'co-production' (and 'co-creation') of city visions, by working with the other three groups represented in the QH model. In this sense 'co-production' can be seen not only as 'a cooperative ethos of enquiry and set of practices' (Perry and Atherton, 2017: 2), but also part of a wider 'co-creation' process, which is a holistic approach, 'beginning with the conception of individual projects, and continuing through to adoption, communication and publication of findings' (MISTRA, 2018). In other words, in an urban visioning context, 'co-creation' can be seen as the combination of co-design, co-production and co-implementation (MISTRA, 2018).

The 'co-creation' role for Universities in visioning has also been highlighted internationally, particularly in relation to urban 
sustainability projects and experiments in cities (Braginskaia and Facer, 2017; Trencher et al., 2013, 2014). Despite this, in the UK, there has, until recently, been a dearth of empirical place-based studies of the future of cities (Tewdwr-Jones and Goddard, 2014; Tewdwr-Jones et al., 2015). However, in January 2015, the Future of Cities Foresight Research Network was established, which brought together universities, cities and other stakeholders to share best practice and help develop long-term visions in specific cities using urban foresight techniques (Cowie et al., 2016; GOS, 2016a). This network incorporated four major cities (Newcastle, Manchester, Cardiff and Liverpool); additional 'city pilots' (Rochdale, Bristol and Milton Keynes); and a 'city vision community' of other cities including Belfast, Birmingham, Cambridge and Reading. For example, in Newcastle the vision process was initiated by the University and drew on the private sector, public sector and civic society (Newcastle City Futures 2065; Goddard and Tewdwr-Jones, 2016; Tewdwr-Jones et al., 2015). There has been some broader reflection on the lessons of the Future of Cities Foresight programme (Cowie et al., 2016; Ravetz and Miles, 2016): for example, Cowie et al. (2016) noted the wider importance of capacity and leadership in city visions, whilst Ravetz and Miles (2016) highlighted the importance of relative power and influence of stakeholder groups in relation to development of the visions. However, to date, with the exception of Newcastle (Goddard and Tewdwr-Jones, 2016; Urban Foresight, 2018) there has been little or no in-depth analysis and critical reflection on individual case studies that were part of this programme and the ensuing implications for other cities.

In the next part of this paper, we therefore summarise the aims and objectives of the research and describe the background and context to the development of the Reading 2050 vision.

\section{Research aim and objectives}

The University of Reading (primarily the School of the Built Environment), Barton Willmore (a major UK planning and design consultancy) and Reading UK CIC (the economic development company for Reading, linked closely to Reading Borough Council - which became more fully involved in the development of the vision later on in the process) came together formally in 2013 to lead and help co-create a city vision for Reading, looking ahead to 2050. This built not only on an initial Reading 2050 Young Professionals Group established by Barton Willmore, but also on previous urban foresight work that the School of the Built Environment at University of Reading had been involved in. There was, from the start, therefore a strong emphasis on collaboration, with the University, industry and local government seeking to work together and engage with Reading residents and community groups to develop the vision.

The aim of this research was to develop a vision, or a shared expectation about a plausible and desirable future for Reading. At that time there was no long-term vision for Reading, ${ }^{1}$ and importantly there was a lack of long-term thinking about the major challenges Reading faced in moving to a 'smart and sustainable' future. This invited two broad research questions which needed to be addressed in the visioning process:

- What should a smart and sustainable Reading look like in 2050?

- How could such a vision be achieved?

The background and context to Reading as a case study are described and explained in the next section. 


\section{Reading: Background and context to the research case study}

Although Reading is not yet officially a 'city', it forms part of one of the most economically vibrant and connected 'small' urban areas in the UK. ${ }^{2}$ Reading, as part of a wider functional urban area (including part of West Berkshire and Wokingham), has a population of 318,000 (2011 figure), and this is set to grow to 362,000 by 2037 (Dixon and Cohen, 2015) (see Figure 2).

Despite its size, Reading's economy, which is highly networked and interconnected nationally and internationally, is one of the strongest in the UK, and is based on advanced business services and high-tech industry which are critically important for innovation and inward investment (Crampton et al., 2010). Reading's economic success and prosperity is based on its physical as well as its virtual connectivity nationally and internationally, but this also presents natural resource and pollution challenges, as it seeks to maintain and enhance its position in an increasingly globalised and competitive market place. Reading is also a classic example of an 'under-bounded' urban area, where its administrative boundary is smaller than its wider functional area and urban footprint (Dixon and Cohen, 2015). The need to tackle these issues is endorsed by Reading's new Local Plan ambitions for 'living within environmental limits'; and 'ensuring a strong, healthy and just society' (Reading Borough Council, 2017), and the need to tackle complex urban sustainability issues have also been recognised in recent reports (Reading Borough Council, 2015; Reading Climate Change Partnership, 2012).

\section{Reading 2050: Research design}

Drawing on the urban foresight methodology used by Eames et al. (2013, 2014a, 2014b) in both Cardiff and Manchester (EPSRC Retrofit 2050 - see 'Background and context' section), the Reading 2050 project used a 'participatory backcasting'

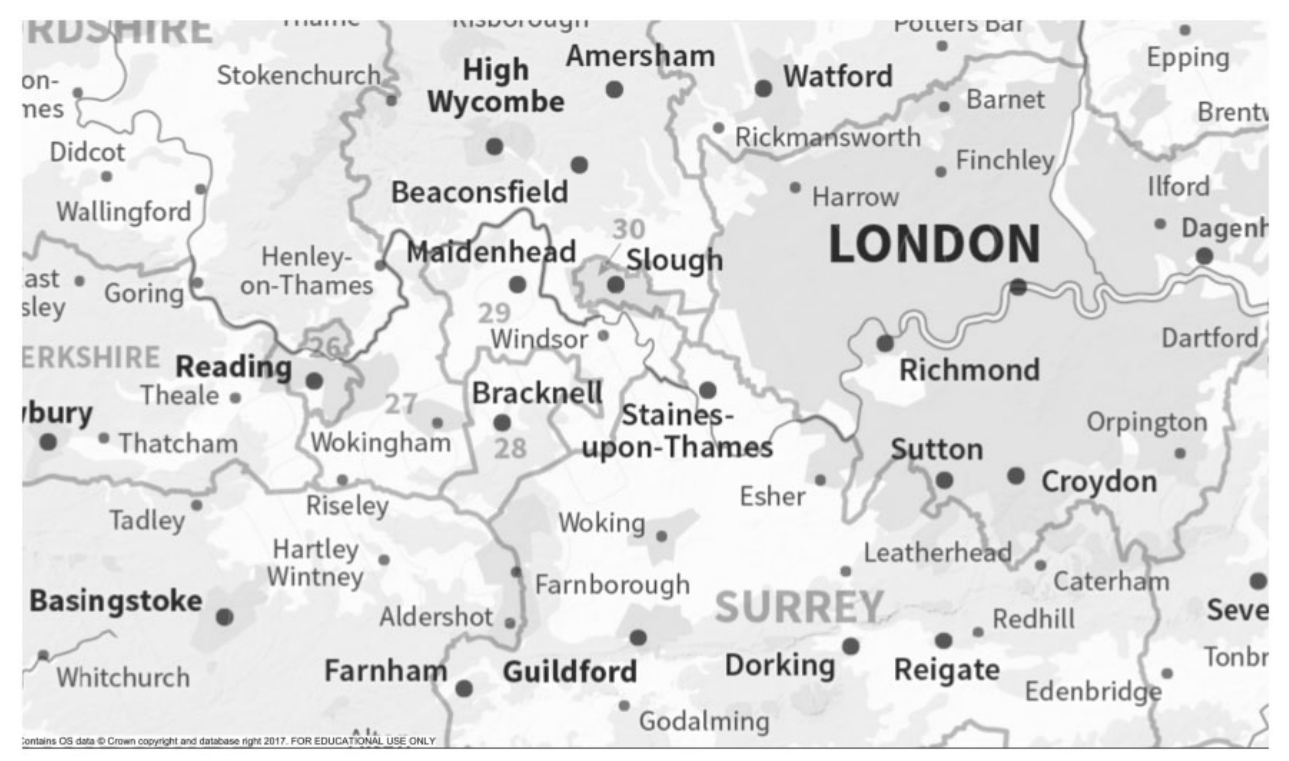

Figure 2. Location of Reading in UK (source: Digimap). 
approach to develop the vision, supported by 'visual conversations' during the workshops which were conducted (Pollastri et al., 2016; Wiek and Iwaniec, 2014). A participatory backcasting approach was used not only because of its successful implementation in previous urban foresight research, but also because the technique (i) incorporates a high degree of stakeholder engagement; and (ii) enables a transparent set of realistic and coherent urban futures to be developed by identifying possible urban futures(s) and the conditions, processes and pathways needed for their realisation (Eames et al., 2017).

Building on this previous research, the Reading 2050 project used an initial participatory 'framing' for stakeholder engagement which was designed to combine elements of a 'smart city' with those of a 'sustainable city'. This was because there is a strategic long-term aspiration to be 'low carbon' by 2050 (through the Reading Climate Change Strategy; Reading Climate Change Partnership, 2012), and also has a strong technology focus in its existing economy (Thames Valley Berkshire LEP, 2016). Moreover, a 2050 time-horizon not only provides space to think beyond today's immediate problems, but also facilitates a greater sense of strategic thinking by identifying desirable as well as undesirable outcomes in line with the UK's climate change target date (Eames et al., 2013). The starting point for the development of the vision was therefore a 'smart and sustainable' city, which can be defined as one that (International Telecommunications Union (ITU), 2014):

'... leverages the ICT infrastructure to:

a. Improve the quality of life of its citizens.

b. Ensure tangible economic growth for its citizens.

c. Improve the well-being of its citizens.

d. Establish an environmentally responsible and sustainable approach to development. e. Streamline and improve physical infrastructure.

f. Reinforce resilience to natural and manmade disasters.

g. Underpin effective and well-balanced regulatory, compliance and governance mechanisms.'

Throughout the process all elements of the vision were tested and validated against these core principles for developing Reading as a smart and sustainable city by 2050 .

Table 1 summarises the main visioning events for the Reading 2050 project. All workshops were run under Chatham House rules, and with a set of clear rules and protocols for courteous engagement.

The process of developing the vision is summarised in Figure 3. Invitees to the workshops were grouped into four broad categories business/industry; government (primarily local); university/academia (University of Reading); and civil society (NGOs) groups. Invitations were made to pre-selected individuals in existing local and regional networks developed by the Reading 2050 partner organisations, and participants were chosen on the basis of their individual knowledge and expertise within these groups. The summary groups and their role in the vision process are set out in Table 1.

During the first workshop, which was designed to scope out the initial ideas for a Reading 2050 vision, three sessions were developed to help think about Reading's long-term future to 2050, in the context of place and environment; people and lifestyle; and economy and employment. The three sessions were as follows:

- What should a smart and sustainable Reading look like in 2050? (Developing the vision): What should Reading look like in 2050, how will it feel, and what will it be like living there? How do we 


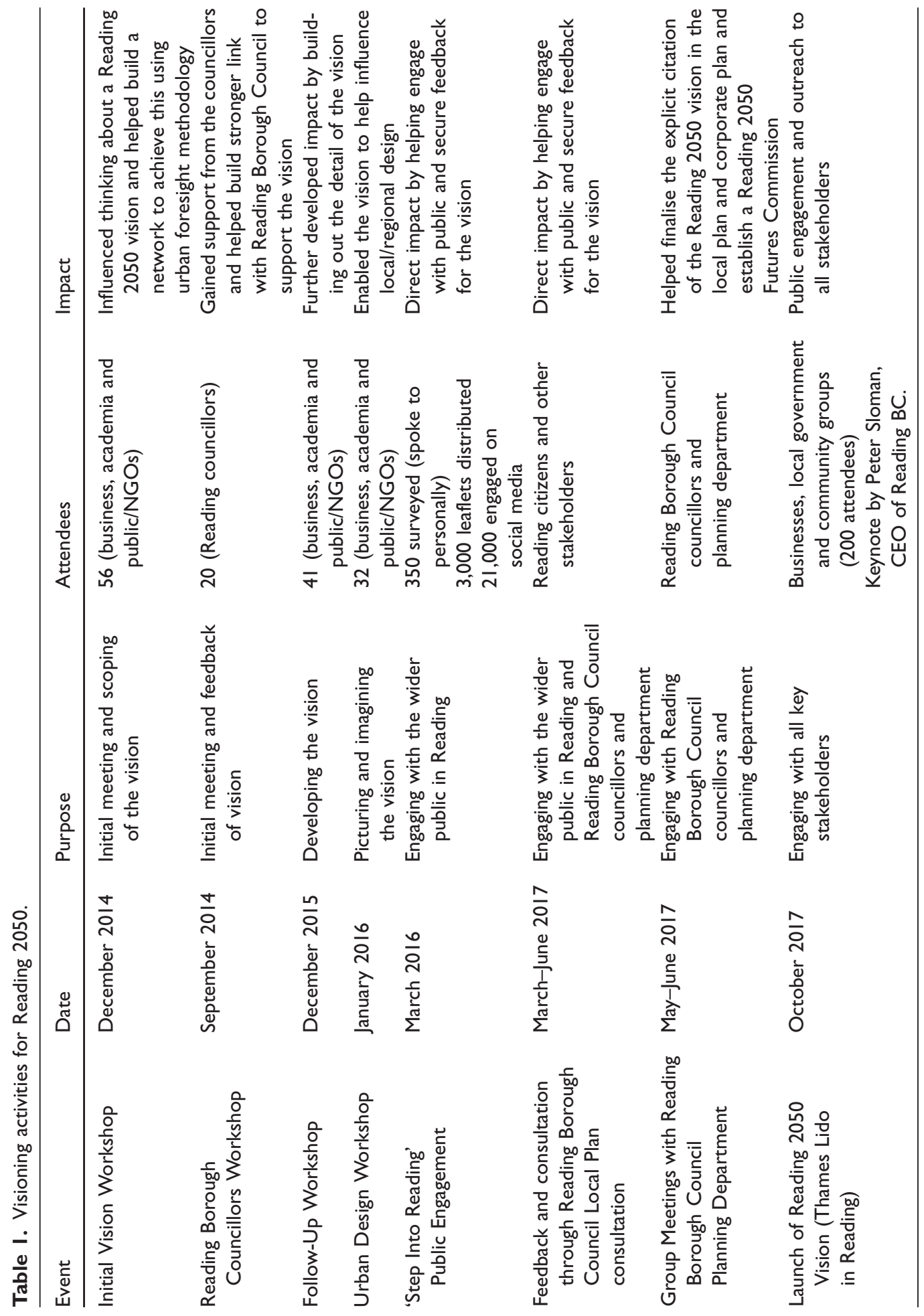




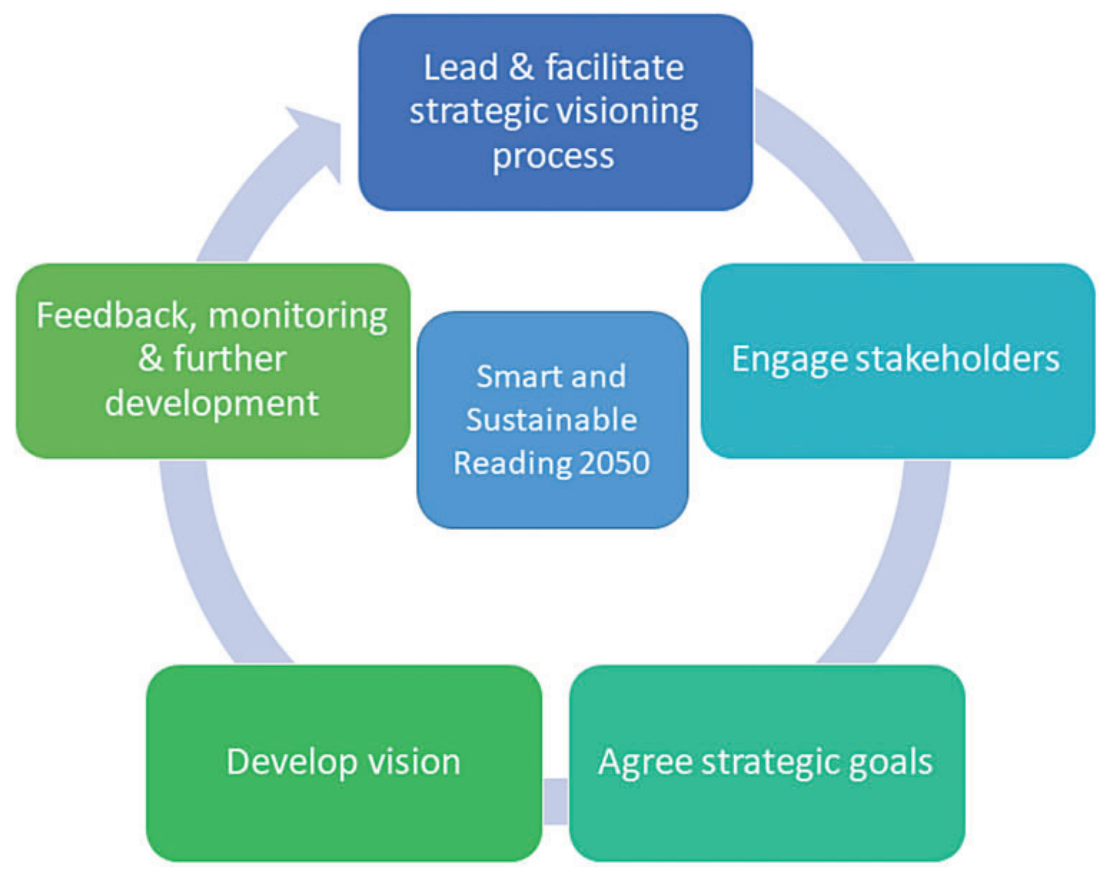

Figure 3. Reading 2050 vision process.

join smart technologies with sustainable thinking in Reading to set it apart, building on the strengths Reading already has? This part of the workshop used group working to focus on place and environment; people and lifestyle and economy and employment.

- How do we achieve a smart and sustainable Reading by 2050? (Developing the roadmaps or pathways to the future): What do we need to do, and by when, to achieve the smart and sustainable vision for Reading? Structured roadmaps and matrices were used to identify challenges and opportunities, based on governance structures; behavioural changes; key technologies and other factors.

- Physical infrastructure, growth and development. This session focused upon integrating the thinking from the earlier sessions into the fabric of Reading. This focused on scoping out the physical changes which could support the smart and sustainable vision, both in the short, medium and long term. Group work examined, through base maps at large and smaller scales, how specific key developments might emerge and what infrastructure changes were needed. 'Postcards from the future' (imagining what the City would be like in 2050) were used to summarise the thinking of groups in the first two sessions, and these were at the heart of developing the urban design futures for the final session.

As a result of this workshop, three interlinked urban futures for Reading emerged: a 'city of rivers and parks'; a 'city of festivals and culture'; and a 'green tech city'. This was then fed back to Reading Borough Council councillors to generate further discussion and feedback, through the direct links Reading UK CIC have with Reading Borough Council. 
These urban futures were then examined in more detail in the second workshop in December 2015. This workshop again used backcasting techniques as a focus for examining:

- What are the strengths and weaknesses of Reading as a place (the 'School Report')? What are Reading's achievements and how could it do better and what needs to change over the longer term to 2050? This session used breakout group discussions to populate matrices and identify the challenges.

- What will a smart and sustainable Reading look like for each of the three urban futures (in terms of place and environment; people and lifestyle; and economy and employment)? This session used group work and narrative descriptions to help identify what the three futures would be like.

- What needs to happen and by when for each of the urban futures? This session used roadmapping techniques to help identify what changes would be needed in Reading to fulfil the alternative futures, in terms of infrastructure, governance or technological development.

The urban design workshop, which was held in January 2016, examined visualisations for each of the three scenarios, based on specific locations including Oxford Road, Thames River frontage, Station Hill and the Abbey Quarter. This workshop brought together urban design experts to help visualise what the three urban futures could look like.

In March 2016, the project also ran a major public engagement event through an exhibition and display on a Reading Buses bus in the town centre. This public engagement activity was supplemented by further activities, including engaging with young people through workshops and art and design competition, and linking with Reading Museum's Where's Reading heading? Happy Museums Project, ${ }^{3}$ which was designed to imagine how Reading's future could be more sustainable.

Finally, during March 2016 to June 2017 the research team engaged in further detailed discussions with Reading Borough Council councillors and the Council planning team to consult on the vision contents and ensure it could be integrated with the local plan (which was in consultation during April 2017 to June 2017) before the vision was launched in October 2017. Ultimately the Local Plan (Reading Borough Council, 2017) and Corporate Plan (Reading Borough Council, 2018) both include a detailed statement of the vision and link their content to the overarching vision.

\section{Reading 2050 vision: An overview}

The overall vision statement that emerged from the series of workshops and participatory engagement was that:

'By 2050, we believe a strong vision will help us to establish Reading as an internationally recognised and economically successful city region. A city where low carbon living is the norm, and the built environment, technology and innovation have combined to create a dynamic, smart and sustainable city with a high quality of life and equal opportunities for all'.

By 2050 Reading will therefore be:

- A cosmopolitan city celebrating and supporting its cultural diversity.

- Retrofitted and developed to create a smart, sustainable, high-quality built environment. 
- A leading destination offering a vibrant city of arts, culture, architecture and public realm.

- Supported by a comprehensive sustainable transport system that accommodates walking and cycling, as well as rapid transport and zero emission vehicles.

- A city of equal opportunities for all and reducing poverty and deprivation.

- A dynamic, resilient and confident city attracting new businesses and entrepreneurs operating sector-wide.

- A leader in smart and green technology and sustainable living solutions.

- A city which has rediscovered and embraced its heritage and landscape.

- Generating a large proportion of its own energy from renewables.

Within this vision, three interrelated urban futures were developed as follows.

'Green Tech City': A city that builds upon its established technology focus. It celebrates and encourages diversity through business incubation units, 'Ideas Factories' and a city centre University campus through which to exhibit and test cutting edge ideas and approaches, no matter what discipline they are emerging from.

'City of Rivers and Parks': A city that recognises how water has shaped much of Reading would celebrate its waterways, opening them up to offer recreational spaces such as animated parks, a lido, food production opportunities and city centre waterside living.

'City of Diversity and Culture': A city that builds on the success of the iconic Reading Festival to deliver arts and culture to people of all ages and ethnicities. Reading would facilitate community interaction and opportunity. The city would integrate, enhance and celebrate our heritage, bringing it to life through modern interpretations and uses of space as well as preservation.

\section{Critical challenges for city visioning: Discussion}

In this section of the paper we firstly reflect on the use of urban foresight methods in developing the Reading 2050 vision, and what critical challenges this raises, particularly in terms of ownership and leadership of the vision. The $\mathrm{QH}$ model highlighted earlier in the paper is then used to analyse the respective roles of the four main groups in the development of the Reading 2050 vision (set within the "participatory domain') and how their interrelationship and involvement has shaped the vision. Finally, we reflect on the wider dissemination and implementation of the vision. In doing this, a comparison is made with the previous literature covered in 'Background and context' section, and also, where possible, drawing comparison with other GoS Future of Cities Foresight city visions (Cowie et al., 2016; Ravetz and Miles, 2016).

\section{Urban foresight methods}

A key issue to address in a city vision project is how the problem is framed from the outset and what comprises the overall ambition(s) or goal(s) of the city vision (Ravetz and Miles, 2016). This also raises the question of whose vision is represented and how such visions are developed: for example, who is part of the initial scoping/ framing? For whom does the visioning process contribute to capacity building and empowerment? How is the vision disseminated to people and the wider community? (McPhearson et al., 2016). It is therefore important to recognise the starting point for such research. 
For example, in the Reading 2050 project it was agreed by the project partners (University of Reading, Baron Willmore and Reading UK CIC) that a normative future should be explored which was 'smart and sustainable', and so the study avoided a dystopic or more negative framing. This also presupposes a beneficial outcome from 'smart' technologies, despite the issues raised in previous research over the potential technocratic marginalisation of citizens from the visioning process (Joss, 2018). Indeed, as Ravetz and Miles (2016) point out, negative forces can also be important to consider, and urban foresight methods also need to find ways of exploring and managing what might be termed 'hard choices and dilemmas'. Restricting discussion to a particular framing can also create the danger of 'closing down' discussion and debate in more controversial areas (Iwaniec and Wiek, 2014). In the case of the Reading 2050 vision, however, it was felt that there were legitimate reasons for setting a more precise 'jumping-off' point for developing a city vision in order to ensure a positive vision is employed which is achievable and gains 'buy-in', but also because time, money and resources are limited.

As the vision was developed through the workshop process it also became clear that the inclusivity of the city vision should also be strengthened. In addition to a strong focus on the built environment (which reflects the interests of the project partners) the city vision therefore also highlights for example, 'a city of equal opportunities for all and reducing poverty and deprivation' (see 'Reading 2050 vision: An overview' section).

\section{Roles and responsibilities of stakeholder groups}

The Reading 2050 vision research was led by University of Reading (School of the Built Environment) in partnership with
Barton Willmore (industry) and Reading UK CIC (the economic development company for Reading. It is therefore characterised as 'academic and business led'. The visioning research, however, also brought together a diverse set of individuals from university/academia (other schools and institutes in the University of Reading); business/industry; government (primarily local); and civil society (NGOs) groups to input into the visioning process. In terms of the $\mathrm{QH}$ model the roles of the four main groups are now examined in more detail in relation to the 'participatory domain' (see Figure 1).

University/academia. The main leadership role in the University was fulfilled by the School of the Built Environment (University of Reading) in a research programme that included elements of reflexive research. The school had been previously involved in research on city visions (EPSRC Retrofit 2050), and so the development of the vision for Reading was seen as a way of anchoring the research interests of the school within the context of Reading. This ambition reflects the anchor role of universities in previous literature, but it should also be noted that such literature highlighted tensions between this role and the power relations created by vision leadership for universities. In the case of Reading there was an altruistic desire to help develop the vision, but also a longerterm ambition that in working with the other project partners the development of the vision could lead to further grant applications and funding for research in the field of smart and sustainable cities. Indeed, this has already led to some success. For example, Thames Valley Berkshire European Regional Development funding (£1.7m) has been secured by industry, Reading Borough Council and the University of Reading to develop smart city projects in Reading and the wider Thames Valley 
Region (including Bracknell, Wokingham and Newbury), which link with the Reading 2050 vision. Reading Borough Council was also the only urban area in south east England to win Heritage Lottery funding for the Great Place project (using Reading 2050 as a project framework). These successes have led to Reading being highlighted as a 'challenger' smart city in the Huawei UK Smart Cities Index (Huawei, 2017).

Business and industry. Barton Willmore is a major UK planning and design consultancy with offices in Reading and elsewhere in the UK. The company played a key role in leading the Reading 2050 vision with the University and Reading UK CIC and helped contribute to the design of materials and facilitation of the workshops. The main aspirations for involvement of the company were to build on its existing capacity and knowledge base in Reading (emphasising its understanding of urban design, placemaking and future-proofing) but also to be seen as influential in helping create the vision through a partnership approach. It therefore played an important role in bringing together a wide range of property industry professionals to participate in workshops, as well as smart city specialists and contacts from other professional and retail service sectors, NGOs and local government. As a result, there was a strong (though by no means exclusive) input from property and built environment professionals. Although it can be challenging for such participants to think longer term and 'outside the box', where a 'possibility' space is provided, people can be encouraged to think about the long-term future. A key issue is however, the extent to which different disciplines and different professionals can work together with other stakeholders and the public to help develop the vision. It may be that in some instances workshop participants do genuinely find it difficult to think 'longer term' beyond the constraints of the present, but by promoting diversity in the workshops, and using participatory processes, this can genuinely help people think innovatively (John et al., 2015).

State/government (local authorities). In the Reading 2050 vision, collaboration was founded on the initial work of the visioning process, and the key 'brokering' role played by Reading UK CIC (the economic development company for Reading), one of the three main partners in the project. Reading UK CIC's main aspirations in the project revolved around developing a vision that would help it promote and strengthen inward investment and economic growth for Reading (Reading UK CIC, 2016). Particularly during the latter stages of the visioning process the link with Reading Borough Council became the basis for further detailed discussions with the council planning department, and also in securing high-level support from the Reading Borough Council leadership, and political support from the councillors in Reading Borough Council. This ensured that the vision became strongly linked with the development of the new Local Plan (which looks ahead to 2036), and is directly referenced within it as an important longer-term framework for Reading (Reading Borough Council, 2017).

A similar synergy is highlighted in the Corporate Plan where the council describes its endorsement of the vision and its commitment to integrating the 2050 ambitions into its priorities (Reading Borough Council, 2018: 4):

'The Council has endorsed this vision and, in its role as community leader, is working alongside other agencies and organisations to realise the vision's ambitions. In the plan we have weaved the vision 2050 objectives into our priorities showing 
how we contribute to the shared aims for Reading'.

This is an important point, because a number of city vision projects in the UK GoS Future of Cities programme failed to engage directly with the local city authorities and institutions (Cowie et al., 2016; Ravetz and Miles, 2016). As Cowie et al. (2016) noted (regarding the GoS Future of Cities Network), taking a long-term view to shaping futures may be seen by some local authority partners as an unnecessary burden, or even a luxury, when service delivery priorities dominate. In Liverpool and Manchester, for example, it has been difficult for the relevant universities to engage with the local authority on fresh visioning because those organisations had already been through previous rounds of city visioning, and an element of 'fatigue' had set in (Cowie et al., 2016).

Perhaps, at least initially, the reluctance of the planning department in Reading Borough Council to be involved reflected not only a period of internal reorganisation, but also, for example, a desire to focus on immediate planning issues rather than long-term issues, and the uncertainty surrounding a 2050 timeline (Freestone, 2012). In the Reading 2050 vision, despite local authority cuts and job losses, the local authority (including the planning department) eventually saw beyond this to endorse and support the project, and saw the benefits of linking the work directly with the new statutory Local Plan. In a positive sense, the exposure of planners and built environment professionals to visioning and the use of foresight techniques may also help them better understand the inherent complexity and uncertainty of cities (Fernández Güell and Lopez, 2016).

Given Reading's 'under-bounded' nature, and the fact that the project was focused on 'Greater Reading' as a functional urban area, it also proved difficult to engage with other neighbouring local authorities (Wokingham BC and Bracknell Forest BC). Some delegates at the early workshops were from these local authorities, but time and resource issues limited their input, and at times it was seen by some as quite controversial using 'Greater Reading' terminology for an area which included a number of local authorities with conflicting and contrasting ambitions. This issue is also of relevance to the Thames Valley Berkshire LEP, which throughout the process has taken a neutral stance on the development of the vision, perhaps reflecting the fact that it needs to take a transparent view of all towns and cities within the sub-region, and not seen to be influencing or taking a 'favoured' perspective on a particular urban area. Certainly, whilst the Reading 2050 vision noted the strategic plans of the LEP, the vision itself focuses very much on Reading itself set within the wider sub-region. ${ }^{4}$

Public/civil society. During the course of the development of the vision the project partners sought input from community groups to help develop the vision. The councillors' workshop and 'Step into Reading' campaign (see Table 1) were very important in terms of public engagement, and further outreach and consultations are planned with the public for 2019/2020. Nonetheless, because the vision is academic and industry-led, the vision inherently reflects the interests of those leading the vision.

\section{Further development and implementation of the vision}

A key issue has been how to fulfil the requirements of 'co-creation' of the city vision through communication, dissemination and outreach to all four stakeholder groups in the $\mathrm{QH}$ model, and, ultimately, to ensure implementation of the vision 
(given the early stages of implementation). As McPhearson et al. (2016) note, a vision in itself cannot be the final end point: there must be 'on the ground' actions to fulfil the vision's ambitions. Promoting and encouraging full engagement with stakeholders (including citizens and community groups in Reading) and communicating the vision was (and is) therefore crucial. For example, the official launch of the vision in October 2017 led to the development of a website, where all the relevant materials (including videos) have been made publicly available, ${ }^{5}$ and also the launch of a Reading 2050 public lecture series at the University in October 2017.

In terms of implementation, besides the direct link to the draft Local Plan and Corporate Plan, a new Reading 2050 'Futures Commission' was established in January 2018. This brings together the University, Reading Borough Council (and Reading UK CIC), and the business/ industry sector as well as civil society groups, and aims to champion the vision and link to the continuing work which will refine the vision as well as bringing together partners in new $\mathrm{R} \& \mathrm{D}$ grant applications. A similar City Futures Development Group was also established in Newcastle and has been successful in terms of developing collaborative ventures between the universities, councils and business in the local area (Cowie et al., 2016).

\section{Conclusions}

The analysis of the development and initial implementation of the Reading 2050 vision through the lens of the $\mathrm{QH}$ has shown that whilst urban foresight tools offer a useful way of developing a city vision, there are critical questions to resolve, including, who is the vision for? and, who leads (and owns) the vision? The 'participatory domain' at the centre of the $\mathrm{QH}$ model is not necessarily one of equivalence therefore. Although visions tend to reflect dominant power relations (and the vision described in this paper is primarily academic and business-led), the Reading 2050 partners have sought to engage inclusively with a variety of groups to develop the vision (adopting a co-created approach which has tried to incorporate reflexivity in research and practice), and the support of Reading Borough Council has been crucial in this respect. Certainly, if we are to develop the long-term, unconstrained thinking in a city vision that is required to move to a more sustainable future, then futures-based studies can offer us a potentially powerful set of tools to help achieve this, and mobilise resources in the best possible way. In this way, provided it nurtures and complements existing spatial plan(s), a long-term city vision can help underpin and support urban spatial planning policies; provide helpful futures-based frameworks for leveraging urban innovation funds in an increasingly competitive environment; and also help overcome the current disconnection between relatively short-term planning horizons and longer-term environmental and socio-economic change in cities. Nonetheless those developing and leading such visions must always reflect on the starting point and the inclusivity of their vision, and what this means for all groups of stakeholders in a city.

\section{Acknowledgements}

Our thanks are owed to all the participants in the Reading 2050 visioning process. Also to the anonymous referees for their helpful comments and suggestions on this paper.

\section{Declaration of Conflicting Interests}

The author(s) declared no potential conflicts of interest with respect to the research, authorship, and/or publication of this article. 


\section{Funding}

The author(s) received no financial support for the research, authorship, and/or publication of this article.

\section{Notes}

1. There had been some previous work on a 'Reading 2020' vision during the 1990s which reflected very largely a Reading Borough Council perspective, and so this also provided a platform and opportunity for further new work.

2. In the already heavily urbanised UK, $70 \%$ of the population living in the top 100 cities (by size) live in smaller/medium sized cities of less than 350,000 people.

3. http://www.readingmuseum.org.uk/getinvolved/projects-consultation/where-s-read ing-heading/

4. Since the Reading 2050 project began, other local visions have also begun to be developed within the LEP sub-region: for example, Basingstoke Horizon 2050: Windsor 2030 and Slough 2040. The LEP has also adopted a similar 'arm's length' approach in the development of these visions.

5. www.reading2050.co.uk

\section{References}

Arnkil R, Jarvesivu A, Koski P, et al. (2011) Exploring Quadruple Helix: Outlining Useroriented Innovation Models. Working Paper, University of Tampere.

Bell S and Paskins J (eds) (2012) Imagining the Future City: London 2062. London: UCL.

Braginskaia E and Facer K (2017) Universities, cities and communities: Co creating urban living: Report from the connected communities programme. University of Bristol, UK.

Brooks M (1988) Four critical junctures in the history of the urban planning profession: An exercise in hindsight. Journal of the American Planning Association 54(2): 241-248.

Bruce S (ed.) (2008) Three Early Modern Utopias: Utopia, New Atlantis and the Isle of Pines. London: Oxford University Press.

BSI (2014) PAS 180. The development of a standard on smart city terminology, BSI.
Carayannis E and Campbell D (2010) Triple helix, quadruple helix and quintuple helix and how do knowledge, innovation and the environment relate to each other? International Journal of Social Ecology and Sustainable Development 1(1): 41-69.

Champion T (2016) People in Cities: The Numbers. Government Office of Science, London.

Costanza R (2000) Visions of alternative (unpredictable) futures and their use in policy analysis. Conservation Ecology 4(1): 5.

Cowie P, Goddard J and Tewdwr-Jones M (2016) The Role of Universities in City Foresight. Government Office of Science, London.

Crampton G, Francis-Brophy E, Meen G, et al. (2010) The Reading diamond: Local economic assessment - Building on strengths, meeting challenges. University of Reading, UK. Available at: www.bracknell-forest.gov.uk/ local-economic-assessment-report.pdf (accessed June 2017).

Dixon T and Cohen K (2015) Towards a smart and sustainable Reading 2050 vision. Town and Country Planning, pp. 20-27. ISSN 0040-9960

Dixon T, Eames M, Hunt M, et al. (eds) (2014) Urban Retrofitting for Sustainability: Mapping the Transition to 2050. Abingdon: Routledge.

Dunn N, Cureton P and Pollastri S (2014) Future cities: A visual history of the future. Government Office of Science, London.

Eames M, Dixon T, Hunt M, et al. (eds) (2017) Retrofitting Cities for Tomorrow's World. Oxford: Wiley-Blackwell.

Eames M, Dixon T, Lannon S, et al. (2014a) Retrofit 2050: Critical challenges for urban transitions. Technical Report. Available at: www.retrofit2050.org.uk (accessed June 2017).

Eames M, Dixon T, May T, et al. (2013) City futures: Exploring urban retrofit and sustainable transitions. Building Research and Information 41(5): 504-516.

Eames MD, Laurentis C, Hunt M, et al. (2014b) Cardiff 2050: City regional scenarios for urban sustainability. Project Report. Cardiff University, UK.

European Union (EU) (2011) An initial assessment of territorial forward planning/foresight projects in the European Union. EU, Brussels. 
Fernández Güell JM (2009) Can foresight studies strengthen strategic planning processes at the urban and regional level?. Paper presented at the City Futures Conference in Madrid, May.

Fernández Güell JM and Lopez J (2016) Cities futures. A critical assessment of how future studies are applied to cities. Foresight 18(5): 454-468.

Fernández Güell JM and Redondo L (2012) Linking territorial foresight and urban planning. Foresight 14(4): 316-335.

Freestone R (2012) Futures thinking in planning education and research. Journal for Education in the Built Environment 7(1): 8-38.

Gaffikin F and Sterrett K (2006) New visions for old cities: The role of visioning in planning. Planning Theory \& Practice 7(2): 159-178.

Garcia-Teran J and Skoglund A (2018) A processual approach for the quadruple helix model: The case of a Regional Project in Uppsala. Journal of the Knowledge Economy, 1-25. Available at: link.springer. com/article/10.1007/s13132-018-0521-5 (accessed August 2018).

Goddard J and Kempton L (2016) The Civic University: Universities in Leadership and Management of Place. Newcastle: Newcastle University/CURDS.

Goddard J, Kempton L and Vallance P (2014) Universities as anchor institutions in cities in a turbulent environment: Vulnerable institutions in vulnerable places. Cambridge Journal of Regions Economy and Society 7(2): 307-302.

Goddard J and Vallance P (2013) The University and the City. Abingdon: Routledge.

Goddard M and Tewdwr-Jones M (2016) City Futures and the Civic University. Newcastle: Newcastle University.

Government Office of Science (GoS) (2016a) Future of cities: Foresight for cities. GOS, London.

Government Office of Science (GoS) (2016b) Future of cities: An overview of the evidence. Government Office of Science, London.

Hambleton R (2014) Leading the Inclusive City: Place-Based Innovation for a Bounded Planet. Bristol: Policy Press.

Hartman C (2011) From urban foresight to urban futures? Potentials and limitations of forward looking activities for integrated urban development. In: Proceedings REAL CORP 2011 (eds M Schrenk, VV Popovitch and $\mathrm{P}$ Zeile), Tagungsband, Essen, 18-20 May 2011.

Hodson M and Marvin S (eds) (2014) After Sustainable Cities?. London: Routledge.

Hogland L and Linton G (2017) Smart specialization in regional innovation systems: A quadruple helix perspective. $R \quad \& \quad D$ Management 48(1): 60-72.

Holste D, Kubecczko K, Schartiger D, et al. (2010) A complimentary architecture to build foresight. Paper presented at the ISPIM - The XXI ISPIM conference dynamics of innovation, Bilbao, Spain, 6-9 June.

Huawei (2017) Smart City Index. Huawei. Available at: e.huawei.com/uk/special_topic/ solution/smart_cities_index_2017 (accessed May 2018).

International Telecommunications Union (ITU) (2014) An overview of smart sustainable cities and the role of information and communication technologies. International Telecommunications Union, Geneva.

Iwaniec D (2013) Crafting sustainability visions Integrating visioning practice, research, and education. Doctoral Thesis, Arizona State University, USA.

Iwaniec D and Wiek A (2014) Advancing sustainability visioning practice in planning: The general plan update in Phoenix, Arizona. Planning Practice and Research 29(5): 543-568.

John B, Keeler LW, Wiek A, et al. (2015) How much sustainability substance is in urban visions? An analysis of visioning projects in urban planning'. Cities 48: 86-98.

Joss S (2018) Future cities: Asserting public governance. Palgrave Communications 4, Article number: 36. Available at: doi.org/10.1057/ s41599-018-0087-7 (accessed August 2018).

Khan S and Zaman A (2018) Future cities: Conceptualising the future based on a critical examination of existing notions of cities. Cities 72: 217-225.

Kimatu JN (2016) Evolution of strategic interactions from the triple to quad helix innovation models for sustainable development in the era of globalization. Journal of Innovation and Entrepreneurship 5(16): 1-7. 
Kubeczko K, Ravetz JVD, Giessen A, et al. (2011) Screening urban foresights and studies supporting forward activities. EFP-Report, European Foresight Platform.

Kummitha R (2018) Entrepreneurial urbanism and technological panacea: Why Smart City planning needs to go beyond corporate visioning? Technological Forecasting and Social Change. DOI: $10.1016 / \mathrm{j}$. techfore.2018.07.010.

McAdam M and Debackere K (2017) Beyond triple helix toward quadruple helix models in regional innovation systems: Implications for theory and practice. $R \& D$ Management 48(1): 3-6.

McPhearson T, Iwaniec D and Bai X (2016) Positive visions for guiding urban transformations towards sustainable futures. Current Opinion in Environmental Sustainability 22: 33-40.

MISTRA (2014) Urban resilience and sustainability, two sides of the same coin? URBES factsheet. Available at: www.mistraurbanfutures.org/ sites/mistraurbanfutures.org/files/urbes_fact sheet_05_web.pdf (accessed February 2018).

MISTRA (2018) Co-creation: Joining forces for change. Available at: www.mistraurbanfu tures.org/en/our-research/co-creation (accessed February 2018).

Mora L, Deakin M and Reid A (2018) Strategic principles for smart city development: A multiple case study analysis of European best practices. Technological Forecasting and Social Change. DOI: 10.1016/j. techfore.2018.07.035.

Newman P and Jennings I (2008) Cities as Sustainable Ecosystems: Principles and Practices. Washington, DC: Island Press.

Office for National Statistics (ONS) (2013) 2011 census analysis - Comparing rural and urban areas of England and Wales. Office for National Statistics, London.

Peel D and Lloyd G (2005) City-visions: Visioning and delivering Scotland's economic future. Local Economy 20(1): 40-52.

Perry B and Atherton M (2017) Beyond critique: The value of co-production in realising just cities?. Local Environment 22(suppl 1): 1-16.

Phdungsilp A (2011) Future studies' backcasting method used for strategic sustainable city planning. Futures 43: 707-714.
Pollastri S, Cooper R, Dunn N, et al. (2016) Visual conversations on urban futures. Participatory methods to design scenarios of liveable cities. In: 2016 Design Research Society 50th anniversary conference, Brighton, UK, 27-30 June.

Ravetz J (2000) City-Region 2050: Integrated Planning for a Sustainable Environment. London: Earthscan/TCPA.

Ravetz J and Miles I (2016) Foresight in cities: On the prospect of a 'strategic urban intelligence'. Foresight 18(5): 469-490.

Reading Borough Council (2015) Corporate plan. Reading Borough Council.

Reading Borough Council (2017) Draft local plan. Reading Borough Council.

Reading Borough Council (2018) Shaping reading's future, corporate plan: 2018-21. Reading Borough Council.

Reading Climate Change Partnership (2012) Reading means business on climate change. Available at: www.reading.gov.uk/media/ 1232/Climate-Change-Strategy/pdf/ClimateChange-Strategy.pdf (accessed June 2012).

Reading UK CIC (2016) Growing opportunity: Reading's Economic Development Plan, 2016-2020. In: Reading UK CIC. Available at: livingreading.co.uk/public/downloads/ SQRiP/Reading\%20Economic\%20Develo pment $\% 20$ Plan_\%20posterfinal.pdf (accessed August 2018).

Royal Society for the Arts (RSA) (2014) UniverCities: The knowledge of the power metros. Royal Society for the Arts, London.

Royal Town Planning Institute (RTPI) (2014) Future Proofing Society. RTPI, London.

Ryan C, Gaziulusoy I, McCormick K, et al. (2016) Virtual city experimentation: A critical role for design visioning. In: Evans $\mathrm{J}$, Karvonen $\mathrm{A}$ and Raven $\mathrm{R}$ (eds) The Experimental City. London: Routledge, pp. $1-18$.

Shipley R and Newkirk R (1999) Vision and visioning in planning: what do these terms really mean?. Environment and Planning B: Planning and Design 26: 573-591.

Swain C (2016) Understanding current city foresight practice. Government Office of Science, London.

Tewdwr-Jones M (2017) Health, cities and planning: Using universities to achieve place 
innovation. Perspectives in Public Health 137(1): 31-34.

Tewdwr-Jones M and Goddard M (2014) A future for cities? Building new methodologies and systems for urban foresight. Town Planning Review 85(6): 776-794.

Tewdwr-Jones M, Goddard $\mathbf{J}$ and Cowie $\mathrm{P}$ (2015) Newcastle City futures 2065: Anchoring universities in cities through urban foresight, Newcastle University, UK.

Thames Valley Berkshire LEP (2016) Thames Valley Berkshire sector proposition: Energy \& environment. Thames Valley Berkshire LEP, UK.

Trencher G, Yarime M, McCormick K, et al. (2014) Beyond the third mission: Exploring the emerging university function of cocreation for sustainability. Science and Public Policy 41: 151-179.

Trencher GP, Yarime M and Kharazi A (2013) 'Co-creating sustainability: Cross-sector university collaborations for driving sustainable urban transformations. Journal of Cleaner Production 50: 40-55.

Urban Foresight (2018) Newcastle's system of systems: The journey towards smart and innovative urban living. Report for Newcastle City Futures and Newcastle University, UK. Available at: www.newcastlecityfutures.org/ wp-content/uploads/2018/07/Newcastle-CityFutures-Systems-Report.pdf (accessed August 2018).

van Waart P, Mulder I and de Bont C (2015) A participatory approach for envisioning a smart city. Social Science Computer Review, October 1: 15.

Weaver PM and Rotmans J (2006) Integrated sustainability assessment: What is it, why do it and how? International Journal of Innovation and Sustainable Development 1(4): 284-303.

Wiek A and Iwaniec D (2014) Quality criteria for visions and visioning in sustainability science. Sustainability Science 9: 497-512. 